\title{
BRONQUITIS BACTERIANA PERSISTENTE - UNA ENFERMEDAD DEL BIOFILM
}

\author{
Comentario del artículo: "Protracted bacterial bronchitis: reinventing an old disease" \\ Arch Dis Child 2013:98:72-76
}

Vanessa Craven MD, Mark Lloyd Everard MD

Department of Respiratory Medicine, Sheffield Children's Hospital, Western Bank, Sheffield,UK

La tos es un síntoma muy frecuente en pediatría. Es un mecanismo normal de protección de la vía aérea para prevenir la aspiración o para expulsar las secreciones de las vías respiratorias inferiores. La tos en general es autolimitada, como en el caso de la impactación de un bolo alimentario en la laringe, o se limita al tiempo de duración de la inflamación por una bronquitis. Sin embargo, si el factor desencadenante no se resuelve, la tos se vuelve crónica, resultando en un marcado deterioro de la calidad de vida. Los lactantes y niños en edad preescolar pueden presentara hasta 12 infecciones respiratorias en un año, con una duración en promedio de 10 a 12 días, por lo tanto no es sorprendente que la tos sea tan frecuente a esta edad. En los casos de tos persistente, la causa más probable es el asma, citándose además como otras causas el reflujo gastroeosofágico y el llamado 'goteo nasal posterior "

Una de las causas de tos crónica que ha recibido mucha atención en los últimos años es la llamada bronquitis persistente o prolongada (BP) (1-5). Para muchos esta parece ser una enfermedad nueva y posiblemente engañosa. En parte, esto se debe a la focalización en el asma por parte de las compañías farmacéuticas y los 'líderes de opinión' y por otro lado a que el concepto de una infección bacteriana crónica de las vías respiratorias inferiores es contrario a lo que se enseña habitualmente. Existe una serie de razones para que la BP reciba una atención creciente en los últimos años, se observe un aparente aumento en su prevalencia y se reconozca que la terapia adecuada puede transformar la calidad de vida de Ios niños afectados, prevenir el desarrollo de bronquiectasias o cuando presente reversibilidad de las alteraciones leves a moderadas observadas en la tomografía computada .

Es importante reconocer que esta condición no es nueva y de hecho antes del desarrollo de antibióticos era común y frecuentemente conducía al desarrollo de bronquiectasias [6], pre-bronquiectasias o bronquitis crónica juvenil. La prevalencia de BP y bronquiectasias en niños disminuyó dramáticamente con los antibióticos (7). El aparente reciente aumento en su prevalencia se debe a mayor identificación y a la reticencia actual para prescribir antibióticos para las infecciones respiratorias en pediatría. Pero también es posible que esto sea una consecuencia inesperada de vacunas diseñadas para prevenir infecciones graves e invasivas, tales como las vacunas neumocócica conjugada y para Hib, permitiéndo la colonización por agentes menos agresivos como el Haemophilus no tipificable y estreptococos no incluidos en la vacuna (8).

Para que se establezca la infección bacteriana crónica se debe considerar la base teórica para el desarrollo de bronquiectasias y comprender el rol del biofilm (9-13). La hipótesis del profesor Peter Cole (14) sigue siendo aceptada para explicar el desarrollo de bronquiectasias: el clearance mucociliar está alterado permitiendo la infección, la cual resulta en inflamación, la que a su vez conduce a daños estructurales en las vías respiratorias comprometiendo la capacidad de eliminar patógenos (Figura 1). Estos cambios se observan precozmente en la tomografía computada, y dan paso a la formación de bronquiectasias a largo plazo, demorando de meses a décadas en aparecer, dependiendo de la intensidad de la inflamación. Estas alteraciones también pueden ocurrir como parte de una bronquitis obliterante, atelectasia persistente, o neumonía grave.

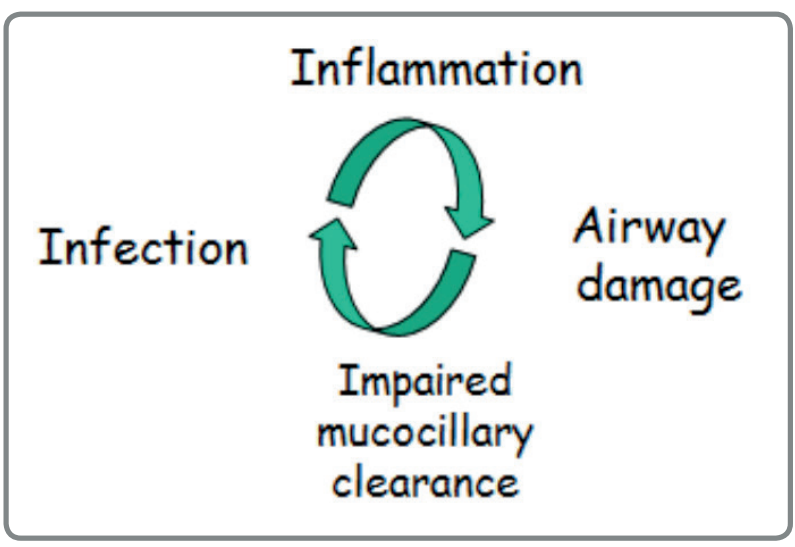

Figura 1.

Hipótesis del círculo vicioso

El reconocimiento de la importancia de los biofilms ha contribuido a la comprensión del comportamiento de agentes patógenos como el Haempphilus influenzae no tipificable y el Estreptococo pneumoniae en bronquios, oído medio y cavidades perinasales (9-13). En lugar de multiplicarse rápidamente como ocurre en los alvéolos y las vías aéreas durante una neumonía, forman biofilms, con una matriz organizada en las vías respiratorias, una actividad metabólica baja, escasa replicación y sobreviviendo a pesar de la inflamación neutrofílica que ellos mismos inducen. Los pacientes tosen debido a la inflamación, 
con las consecuencias de alteración durante sueño, junto con la tos característica al acostarse o levantarse por la mañana y con el ejercicio. Durante la infección viral el biofilm libera células planctónicas que contribuyen al aumento de la inflamación y exacerbación (15). Debido a la presencia de mucus, a la gruesa matriz producida por los microorganismos, a la baja tasa metabólica, es difícil erradicar estos agentes infecciosos. La tos tomará 10 a 14 días en resolver.

Como se señaló anteriormente, la alteración del clearance mucociliar sería el evento inicial. La traqueobroncomalacia, presente en muchos de estos pacientes sería un factor agravante. No es sorprendente que la condición comience en los primeros años de la vida $(3,7)$. No se han realizado estudios de historia natural ni de prevalencia por lo que no está claro cuántos de aquellos que presentan una bronquitis persistente desarrolla síntomas de larga duración. Estudios de cohorte indican que las personas con daño estructural de la vía aérea mejoran en forma natural en la severidad de los síntomas durante la segunda y tercera décadas de la vida y luego muestran deterioro (7). La impactación mucosa y la inflamación del epitelio asociado con asma mal controlada también parece ser una causa significativa. Entonces la BP es a la vez un diagnóstico alternativo y una potencial comorbilidad.

El daño de la vía aérea no es una enfermedad, sino la apariencia radiológica o patológica resultante de la inflamación asociada con la enfermedad que es la bronquitis bacteriana persistente. En ausencia de infección, la inflamación asociada a cambios estructurales de la vía aérea no causa síntomas (a menos que esta sea grave).

Es importante tener en cuenta la BP como diagnóstico paralelo en un niño asmático en quien la tos es el síntoma predominante sobre todo si se trata de una tos húmeda. Sin embargo no hay aspectos de la historia que permitan diferenciarl la BP del asma. El sobre o subdiagnóstico de ambos es frecuente. Se puede considerar una prueba terapéutica para establecer el diagnóstico definitivo.

\section{REFERENCIAS}

1. Craven V, Everard ML. Protracted bacterial bronchitis: reinventing an old disease. Arch Dis Child. 2013; 98: 72-6

2. Chang A B, Redding G J, Everard M L. State of the Art Chronic wet cough: protracted bronchitis, chronic suppurative lung disease and bronchiectasis. Pediatr Pulmonol 2008; 43: 519-531

3. Donnelly D E, Critchlow A, Everard M L. Outcomes in Children Treated for Persistent Bacterial Bronchitis. Thorax 2007; 62: 8084

4. Marchant J M, Masters I B, Taylor S M, Cox N C, Seymour G J, Chang A B. Evaluation and outcome of young children with chronic cough. Chest 2006; 129: 1132-1141

5. Chang AB, Byrnes CA, Everard ML. Diagnosing and preventing chronic suppurative lung disease (CSLD) and bronchiectasis. Pediatr Resp Rev 2011; 12: 97-103
6. Field C E. Bronchiectasis in childhood: II. Aetiology and Pathogenesis, Including a Survey of 272 Cases of Doubtful Irreversible Bronchiectasis. Pediatr 1949; 4: 231-248

7. Field CE. Bronchiectasis. Third report on a follow-up study of medical and surgical cases from childhood. Arch Dis Child. 196;44:551-61

8. Priftis KN, Litt D, Manglani S, Anthracopoulos MB, Thickett K, Tzanakaki G, Fenton P, Syrogiannopoulos GA, Vogiatzi A, Douros K, Slack M, Everard ML. Bacterial bronchitis caused by Streptococcus pneumoniae and nontypable Haemophilus influenzae in children: the impact of vaccination. Chest. 2013; 143: $152-7$

9. Dagan R, Leibovitz E, Greenberg D, Bakaletz L, Givon-Lavi N. Mixed pneumococcal-nontypeable Haemophilus influenzae otitis media is a distinct clinical entity with unique epidemiologic characteristics and pneumococcal serotype distribution. J Infect Dis. 2013; 208: 1152-60

10. Bakaletz LO. Bacterial biofilms in the upper airway - evidence for role in pathology and implications for treatment of otitis media. Paediatr Respir Rev. 2012; 13: 154-9

11. Marsh RL, Thornton RB, Smith-Vaughan HC, Richmond P, Pizzutto SJ, Chang AB. Detection of biofilm in bronchoalveolar lavage from children with non-cystic fibrosis bronchiectasis. Pediatr Pulmonol. 2014 Mar 18. doi: 10.1002/ppul.23031 12. Chao Y, Marks LR, Pettigrew MM, Hakansson AP Streptococcus pneumoniae biofilm formation and dispersion during colonization and disease. Front Cell Infect Microbiol. 2015 Jan 13;4:194. doi: 10.3389/fcimb.2014.00194

13. Tikhomirova A, Kidd SP. Haemophilus influenzae and Streptococcus pneumoniae: living together in a biofilm. Pathog Dis. 2013; 69: 114-26

14. Cole PJ. Inflammation: a two-edged sword--the model of bronchiectasis. Eur J Respir Dis Suppl. 1986;147:6-15

15. Chattoraj SS, Ganesan S, Jones AM, Helm JM, Comstock AT, Bright-Thomas R, LiPuma JJ, Hershenson MB, Sajjan US. Rhinovirus infection liberates planktonic bacteria from biofilm and increases chemokine responses in cystic fibrosis airway epithelial cells. Thorax. 2011; 66: 333-9

16. Hall-Stoodley L, Stoodley P, Kathju S, Høiby N, Moser C, Costerton JW, Moter A, Bjarnsholt T. Towards diagnostic guidelines for biofilm-associated infections. FEMS Immunol Med Microbiol. 2012; 65: 127-45. 